Article

\title{
Chronoamperometric Observation and Analysis of Electrocatalytic Ability of Single Pd Nanoparticle for Hydrogen Peroxide Reduction Reaction
}

\author{
June Young Park, Ki Jun Kim ${ }^{\circledR}$, Hyeryeon Son and Seong Jung Kwon * \\ Department of Chemistry, Konkuk University, 120 Neungdong-ro Gwangjin-gu, Seoul 143-701, Korea; \\ pa7673rk@naver.com (J.Y.P.); kim573252@naver.com (K.J.K.); envy5255@daum.net (H.S.) \\ * Correspondence: sjkwon@konkuk.ac.kr; Tel.: +82-2-450-0429
}

Received: 21 September 2018; Accepted: 23 October 2018; Published: 26 October 2018

\begin{abstract}
The current generated by the collision of a single nanoparticle (NP) of palladium (Pd) on a gold $(\mathrm{Au})$ ultramicroelectrode (UME) surface was observed using an electrocatalytic amplification method. The hydrogen peroxide reduction reaction was used for the electrocatalytic reaction because the hydrogen peroxide reduction reaction has no gas-phase product, which would induce rapid signal decay. The electrocatalytic current resulting from a single Pd nanoparticle on the Au UME shows a staircase response with accompanying slow current decay. The applying potential and concentration of hydrogen peroxide were optimized for clear distinction of signal. The height of the current step and signal frequency were analyzed and compared with the theoretical expectation. The analysis of the electrocatalytic activity of single Pd NPs provides insight toward their future application.
\end{abstract}

Keywords: palladium; single nanoparticle; collision; electrocatalytic amplification; hydrogen peroxide

\section{Introduction}

Advances in nanoscience and nanotechnology have given rise to the need to analyze nanomaterials at the level of a single nano-entity. The individual property of single nano-entity is more advisable than the ensemble-averaged properties of polydispersed system for the study of nanomaterial because the physicochemical properties of nanomaterials are very sensitive to their size, facet, surfactant, or supporter. However, the study of the electrocatalytic or other properties of a nanoparticle (NP) at the single NP level is highly challenging, because of the difficulty associated with identifying the weak signal among noise [1,2]. Recently, many electrochemistry groups have attempted to investigate the electrocatalytic properties of NPs at the single NP level using an electrochemical approach [3-20]. This technique, which is based on ampero- [3-14], potentio- [15,16], or coulo-metric [17] methods, exploits the electrocatalytic difference between an NP and a small electrode, such as an ultramicroelectrode (UME).

To achieve this, an electrochemical cell consisting of an UME as the working electrode and an electrolyte solution containing the NPs is required. Whenever the NPs diffuse and collide on the UME, the change in electric signal at the moment of collision is observed. In this regard, the electrocatalytic amplification (EA) method [3-20], which was suggested by Bard group and is the most general method of this technique, was used for a highly electroactive metal or metal oxide NP. Whenever the active NPs collided on the inert UME, the electrocatalytic signal generated by an NP was recorded. A metallic NP with poor or no electrocatalytic activity can be detected by using direct particle electrolysis $[6,18]$, which is based on the self-redox reaction of the NP itself. An insulating NP [19] (or soft particle), such as a nano-emulsion [20] or biomolecule [21,22], can be detected by using an UME blocking strategy $[7,19]$ based on hindering the electrochemical reaction of the UME by the NP. 
Noble metals, such as Pt, are widely studied by EA methods [3,4]. Even though Pt has good electrocatalytic activity for many useful electrochemical reactions, many researchers attempted to substitute it with a less expensive metal because of the limited natural reserves and high cost of $\mathrm{Pt}$. One of the candidates to substitute $\mathrm{Pt}$ as an electrocatalyst is palladium (Pd). The versatile electrocatalytic activities of Pd have resulted in this metal being well studied as an electrocatalyst [23-25]. However, few studies at the single NP level have been reported for Pd NPs. Recently, Zare group reported firstly the collision of a single NP of Pd for the hydrazine oxidation reaction using a chronopotentiometric method [26].

In this study, we investigated the collision of a single Pd NP on an UME with chronoamperometric method using hydrogen peroxide reduction as the electrocatalytic reaction for EA. Here, hydrogen peroxide reduction $[3,27,28]$ was selected instead of hydrazine oxidation [4], which is most widely used as the electrocatalytic reaction in experiments involving the collision of a single NP, for two reasons. First, the hydrogen peroxide reduction reaction does not have a gas-phase product. According to many previous studies, the current response of a single NP collision depends on various variables, including the electrochemical reaction product, resulting in a "blip" or "staircase" response [29]. When a gas-phase product is involved, the reaction is hindered by the adsorption of the produced gas on the surface of the NP, thereby inducing the decay of the current response. Therefore, the hydrogen peroxide reduction reaction, which can avoid this kind of current decay, was selected because the "staircase" response is much easier to analyze than the "blip" response. The second reason is the need to avoid excessive self-oxidation of the Pd NP. If we used an oxidation reaction, such as hydrazine oxidation, an anodic potential would be applied to the UME. This could affect the oxidation state of the NP and could ultimately change the electrocatalytic activity of the NP. Therefore, a reduction reaction is a much safer option for the self-oxidation of a Pd NP. In addition, the detection of hydrogen peroxide is important in biomedical and environmental applications.

Not only the shape of the current response, we also investigated the peak intensity and frequency whereby the Pd NP undergoes collisions. The shape corresponds to the mechanism or the change of the electrocatalytic ability of the Pd NP as a function of time. The peak intensity and frequency indicate the size and concentration of the Pd NP, respectively. The experimental values were recorded and analyzed by performing a theoretical calculation. In conclusion, the observation and analysis of the electrocatalytic activity of a single Pd NP for hydrogen peroxide reduction reaction using EA method can provide insight toward their application.

\section{Materials and Methods}

\subsection{Reagent}

Palladium(II) chloride $\left(\mathrm{PdCl}_{2}, 99 \%\right)$, sodium borohydride $\left(\mathrm{NaBH}_{4}, \geq 96 \%\right)$, potassium phosphate monobasic $\left(\mathrm{KH}_{2} \mathrm{PO}_{4}, \geq 99 \%\right)$, and citric acid $\left(\mathrm{C}_{3} \mathrm{H}_{5} \mathrm{O}(\mathrm{COOH})_{3}, \geq 99.5 \%\right)$ were obtained from Sigma-Aldrich (Aldrich, St. Louis, MO, USA). Hydrochloric acid ( $\mathrm{HCl}, 35.0-37.0 \%)$, and hydrogen peroxide $\left(\mathrm{H}_{2} \mathrm{O}_{2}, \sim 34.5 \%\right)$ were obtained from Samchun Pure Chemical Co., Ltd. (Pyeongtaek, Korea). Dipotassium hydrogen phosphate $\left(\mathrm{K}_{2} \mathrm{HPO}_{4}, 99.0 \%\right)$ was obtained from Junsei Chemical Co., Ltd. (Tokyo, Japan). All chemicals were used as received. Ultrapure water $(\geq 18 \mathrm{M} \Omega$, Millipore, Bedford, MA, USA) was used in all experiments.

\subsection{Preparation of $P d N P$}

An aqueous solution of $0.5 \mathrm{mM}$ of $\mathrm{PdCl}_{2}$ was prepared by completely dissolving $1.773 \mathrm{mg}$ of $\mathrm{PdCl}_{2}$ in $20 \mathrm{~mL}$ of $1 \mathrm{mM} \mathrm{HCl}$ under ultrasonic treatment for $30 \mathrm{~min}$. After that, $3.842 \mathrm{mg}$ of citric acid $(1 \mathrm{mM})$ was dissolved in the mixed solution with magnetic stirring for $5 \mathrm{~min}$ at $80^{\circ} \mathrm{C}$ and $2 \mathrm{~mL}$ of $0.1 \mathrm{M} \mathrm{NaBH}_{4}$ aqueous solution was slowly added to the mixture under magnetic stirring. The color of the solution became dark brown [30]. 


\subsection{Preparation of $U M E$}

The Pd and Au UMEs were prepared using the following method. Briefly, Pd wire with a $10 \mu \mathrm{m}$ radius or Au wire with a $6.35 \mu \mathrm{m}$ radius was sealed in glass after rinsing with methanol and water. The electrode was then polished with alumina powder water suspension to a mirror face. The surface area was checked with standard redox electrochemistry of ferrocene in methanol [3-5].

\subsection{Electrochemical Cell and Technique}

All experiments were conducted in a conventional three-electrode cell at room temperature. The working electrode was the UME. A platinum electrode was used as the counter electrode and a standard $\mathrm{Ag} / \mathrm{AgCl}$ electrode as the reference electrode. All electrochemical experiments were performed in $0.1 \mathrm{M}$ phosphate buffer $(\mathrm{PB})$ solutions. The cyclic voltammetry was done at a $100 \mathrm{mV} / \mathrm{s}$ scan rate in $\mathrm{pH} 13$ solution. The chronoamperometric curves were obtained with $50 \mathrm{~ms}$ of data acquisition time. The NP was injected into the electrolyte solution after starting the chronoamperometric measurement usually $10 \mathrm{~s}$ later.

\subsection{Instrumentation}

Electrochemical experiments were performed with a $\mathrm{CHI} 660 \mathrm{~A}$ electrochemical analyzer $(\mathrm{CH}$ Instruments, Austin, TX, USA). The $\mathrm{pH}$ of the solution was measured by a EZRODE P1 (EZSEN, Seoul, Korea). The transmission electron microscopy (TEM) image was obtained from the Korea Basic Science Institute (Seoul, Korea) using a Tecnai G2 F30ST Instrument (FEI Company, Hillsboro, OR, USA).

\section{Results and Discussion}

The size of Pd nanoparticles (NPs) was determined by acquiring TEM images as shown in Figure 1. The average diameter of Pd NPs was approximately $11( \pm 3) \mathrm{nm}$. The concentration of stock solution of Pd NPs was calculated from the concentration of the Pd precursor divided by the average number of Pd atoms contained in a particle. The average number of Pd atoms in a $11 \mathrm{~nm}$ sized Pd NP was estimated as $\sim 4.74 \times 10^{4}$ atoms. The average number of atoms per particle was calculated by the proportional basis of density and radius between single atom and NP.
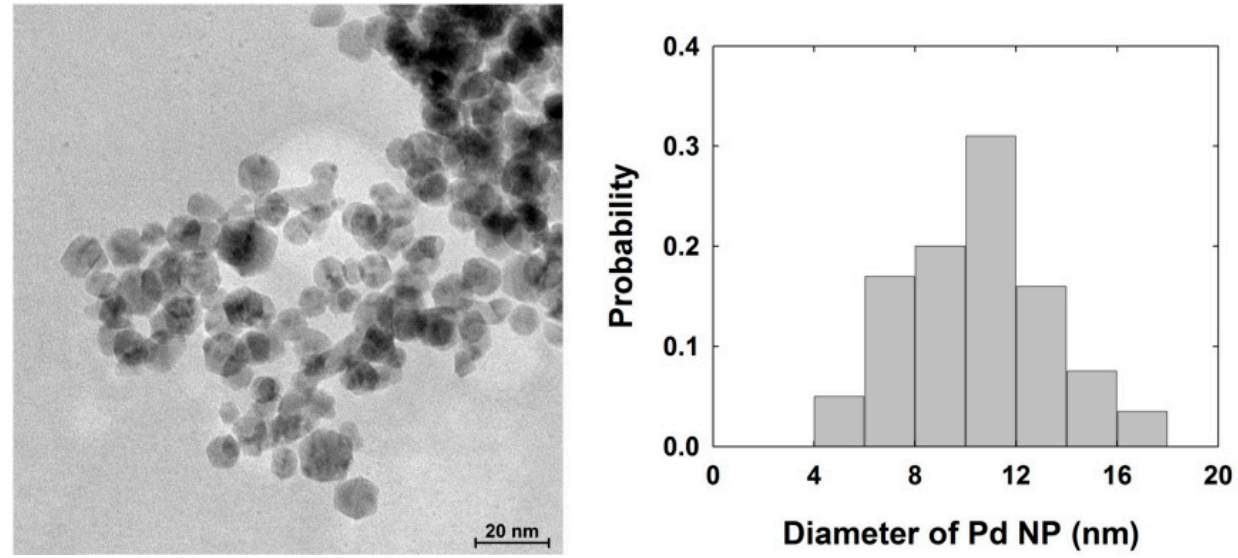

Figure 1. Transmission electron microscopy (TEM) image of palladium (Pd) nanoparticle (NP) and its size distribution. The scale bar is $20 \mathrm{~nm}$.

Electrocatalytic amplification (EA) methods are designed to detect collisions of a NP on an inert electrode. The observation of the current response of a single NP collision depends on the kind of NPs and the ultramicroelectrode (UME). Even the same NP sometimes shows different signal responses for the collision with different UMEs. This is because the adsorption behavior between the NP and UME is very sensitive to the materials of which the NP and UME consist. We found the Pd NP on Au 
electrode to show good electrocatalytic activity for hydrogen peroxide reduction. Therefore, an $\mathrm{Au}$ UME was selected as inert electrode to observe the collision of the Pd NP.

Next, we investigated the electrocatalytic ability of both an Au and a Pd UME for the hydrogen peroxide reduction to determine an appropriate potential adaptable for the electrocatalytic reaction by only the NP excluding the UME. As shown in Figure 2a, the Au and Pd UMEs exhibited different behavior for the electrochemical reduction of hydrogen peroxide. At the Pd UME, the onset potential of the hydrogen peroxide reduction reaction is less negative than that at the Au UME. As expected, the Pd UME showed considerable current even though the Au UME has low electrocatalytic activity for the hydrogen peroxide reduction. To confirm that this reduction current originated from the hydrogen peroxide reduction rather than proton reduction or other reactions, the change in the reduction current at the Pd UME was investigated at various hydrogen peroxide concentrations from 0 to $100 \mathrm{mM}$. As shown in Figure $2 \mathrm{~b}$, the steady-state current increased proportional to the concentration of hydrogen peroxide. Therefore, the main contribution to the reduction current is by hydrogen peroxide reduction in this potential window and at this $\mathrm{pH}$. However, the potential range for which a steady-state current exists at the Pd UME is not leveled and the background current at the $\mathrm{Au}$ UME also increases slightly below $-0.2 \mathrm{~V}$ as shown in Figure 2 and Figure S1 (see the Supporting Information, SI). This might be a contribution from the proton reduction reaction or other reactions. When the collision current generated by the NP was recorded at $-0.2 \mathrm{~V}$ or more negative values by chronoamperometry, the background current fluctuated considerably (Figure S2). The regular pattern of current fluctuation was obtained at this case, which seems due to the regular bubble production by the side reaction such as hydrogen evolution [31]. Thus, it was difficult to distinguish the signal from the noise. This prompted us to select $-0.15 \mathrm{~V}$ at which to conduct the chronoamperometric experiment to observe the collision of a single NP with the aim of minimizing the contribution of side reactions to the background current.
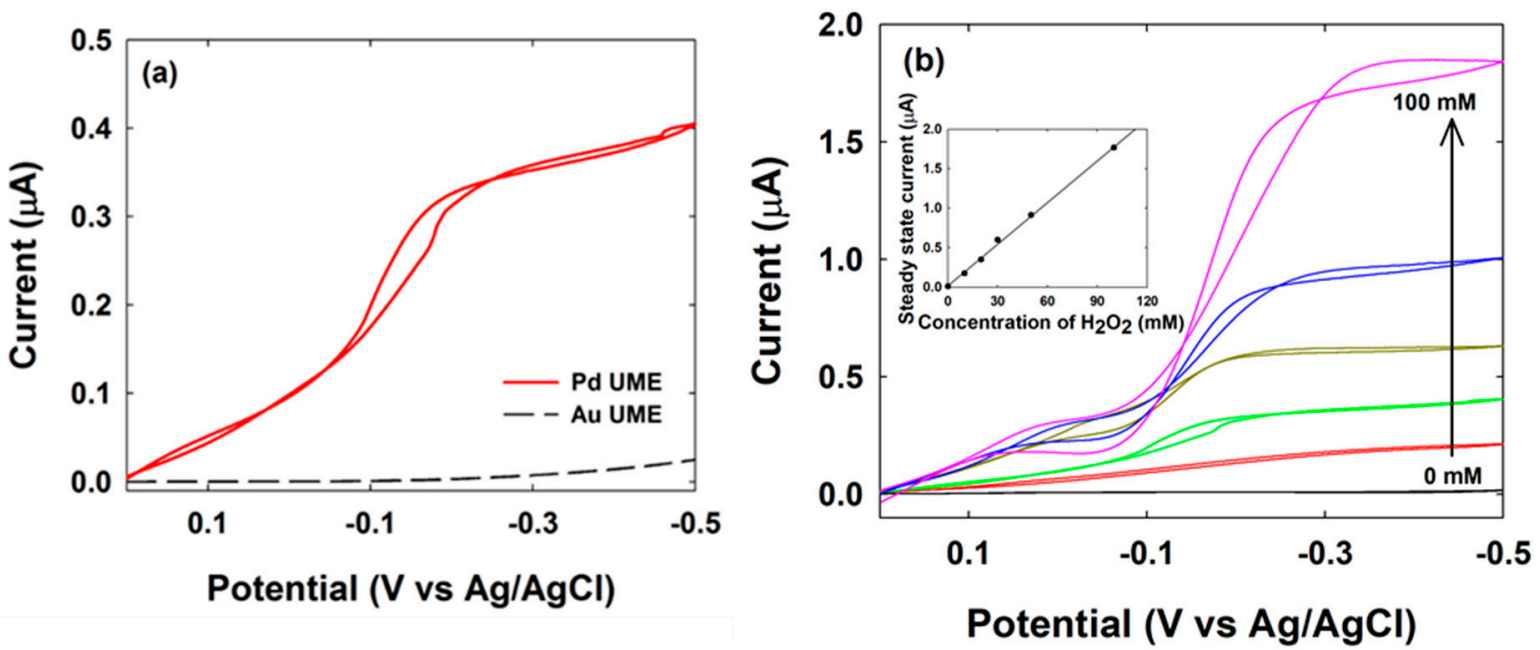

Figure 2. Cyclic voltammograms of hydrogen peroxide reduction reaction at: (a) Au (black dashed) or $\mathrm{Pd}$ (red solid) ultramicroelectrode (UME) (radius 6.35 and $10 \mu \mathrm{m}$, respectively) in a $0.1 \mathrm{M}$ phosphate buffer (PB) solution ( $\mathrm{pH}$ 6.8) containing $20 \mathrm{mM} \mathrm{H}_{2} \mathrm{O}_{2}$; (b) Pd UME in $0.1 \mathrm{M}$ PB solution (pH 6.8) containing $0,10,20,30,50$, and $100 \mathrm{mM} \mathrm{H}_{2} \mathrm{O}_{2}$. Scan rate was $100 \mathrm{mV} / \mathrm{s}$.

Similarly, the signal distribution from the noise background current was more problematic at higher concentrations of hydrogen peroxide. Therefore, the hydrogen peroxide concentration was optimized to $20 \mathrm{mM}$ (Figure S3).

The electrocatalytic activity of a single $\mathrm{Pd} \mathrm{NP}$ was investigated by obtaining the chronoamperometric measurement as shown in Figure 3. The collision of the Pd NP with the Au $\mathrm{UME}$, held at a potential of $-0.15 \mathrm{~V}$, led to the observation of a staircase-like response of the current 
transient. However, the instant increase in the current is not maintained at this level and shows a very slow decay.
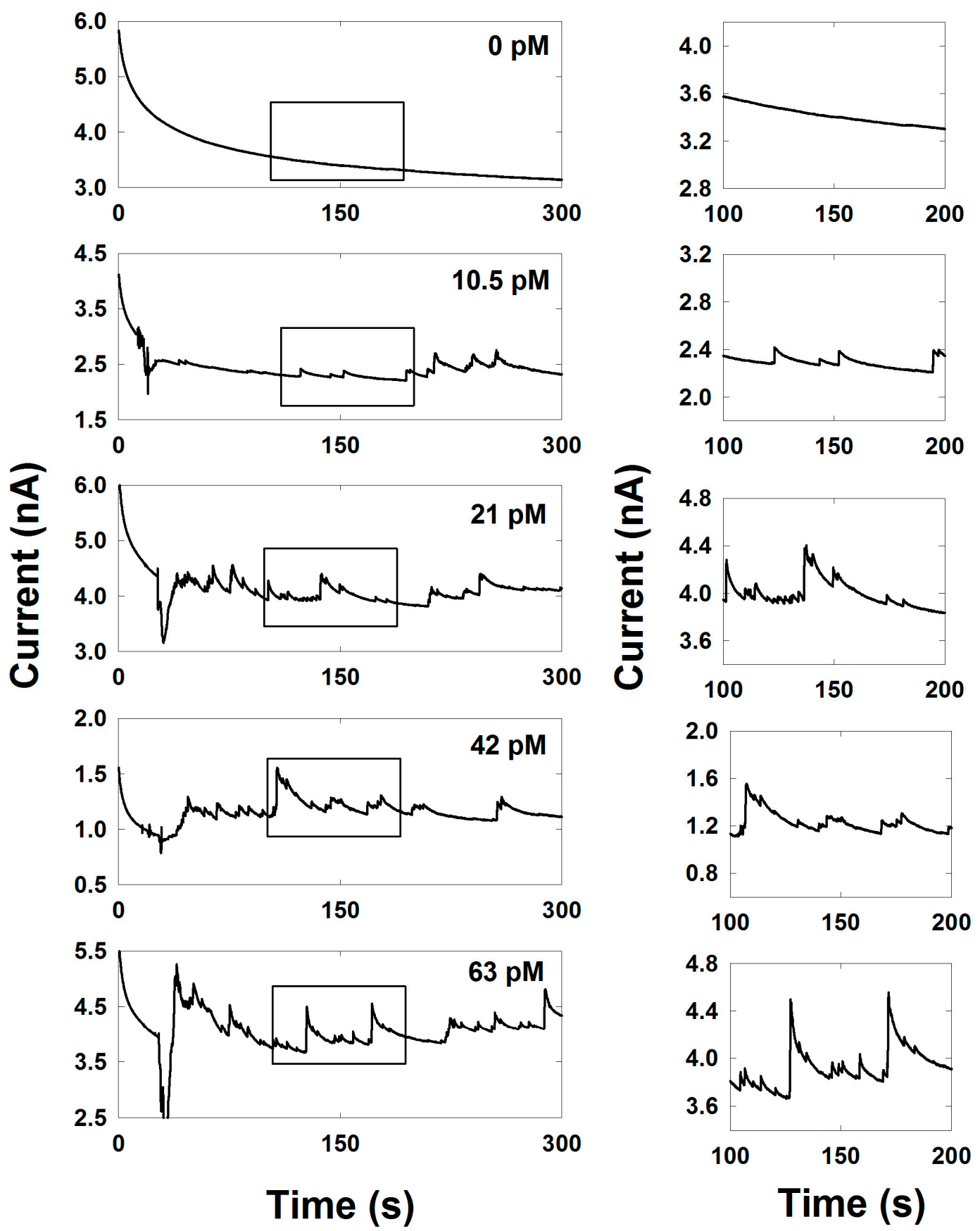

Figure 3. Chronoamperometric curves for single Pd NP collisions at an applied potential of $-0.15 \mathrm{~V}$ at the Au UME with different Pd NP concentrations $(0,10.5,21,42$, and $63 \mathrm{pM})$ in a $0.1 \mathrm{M}$ PB solution containing $20 \mathrm{mM} \mathrm{H}_{2} \mathrm{O}_{2}$. The data acquisition time was $50 \mathrm{~ms}$.

In many previous studies, relatively fast decay, resulting in a "blip" response, was observed when the single NP collision system consisted of an electrocatalytic reaction with a gas-phase product. The Pt NP/Ni UME/hydrazine oxidation system exhibits a current response change from "staircase" to "blip" under specific conditions [29]. Likewise, the $\mathrm{IrO}_{\mathrm{x}} \mathrm{NP} / \mathrm{Pt} \mathrm{UME} /$ water oxidation system has a "blip" response due to the oxygen gas product that forms an enclosure on the surface of the NP [32]. Therefore, these gas-phase products, such as nitrogen in hydrazine oxidation or oxygen in water 
oxidation, are responsible for the "blip" response by attaching to the surface of the NP and preventing the NPs from participating in electron transfer. However, in this system, the only reaction product of hydrogen peroxide reduction is water. Therefore, there seems to be another reason for the deactivation of the Pd NP as manifested by the very slow decay of the current response, such as the adsorption of impurities or a change in the state of the NP or by the gas-phase product of side reaction such as proton reduction.

In previous studies, collision experiments with the Pd NP using the hydrazine oxidation reaction showed a "blip" response [26]. However, when the hydrogen peroxide reduction was used with a Pt $\mathrm{NP}$, a "staircase" response was obtained similar to our result [3]. When hydrogen peroxide oxidation was used for the detection of a $\mathrm{RuO}_{\mathrm{x}} \mathrm{NP}$, the signal showed the "blip" response due to the gas-phase product oxygen [27]. Therefore, single-NP detection was accomplished by using hydrogen peroxide reduction, which causes the "staircase" response because of the absence of a gas-phase product.

The collision frequencies were investigated in the presence of various concentrations $(0,10.5$, 21,42 , and $63 \mathrm{pM}$ ) of Pd NPs. The frequency was proportional to the concentration of the NPs as expected and as shown in Figures 3 and 4 . The experimentally obtained collision frequency was $0.0048 \mathrm{~s}^{-1} \mathrm{pM}^{-1}$. However, the collision frequency was approximately three orders of magnitude lower than the value $\left(0.681 \mathrm{~s}^{-1} \mathrm{pM}^{-1}\right)$ calculated by the Fick's law $[33,34]$ :

$$
f_{p}=4 D_{N P} C_{N P} r_{U M E}
$$

where $C_{N P}$ is the concentration of NPs, $r_{U M E}$ is the radius of the UME, $D_{N P}$ is the diffusion coefficient of NP, which is estimated as $4.46 \times 10^{-7} \mathrm{~cm}^{2} \mathrm{~s}^{-1}$ by the Einstein-Stokes equation. The lower frequency originates from the aggregation of Pd NPs in electrolyte solution, the loss of NPs by adherence to the cell wall or precipitate, or loss of signal by noisy background current or a lower adsorption coefficient between Pd NPs and the Au UME.

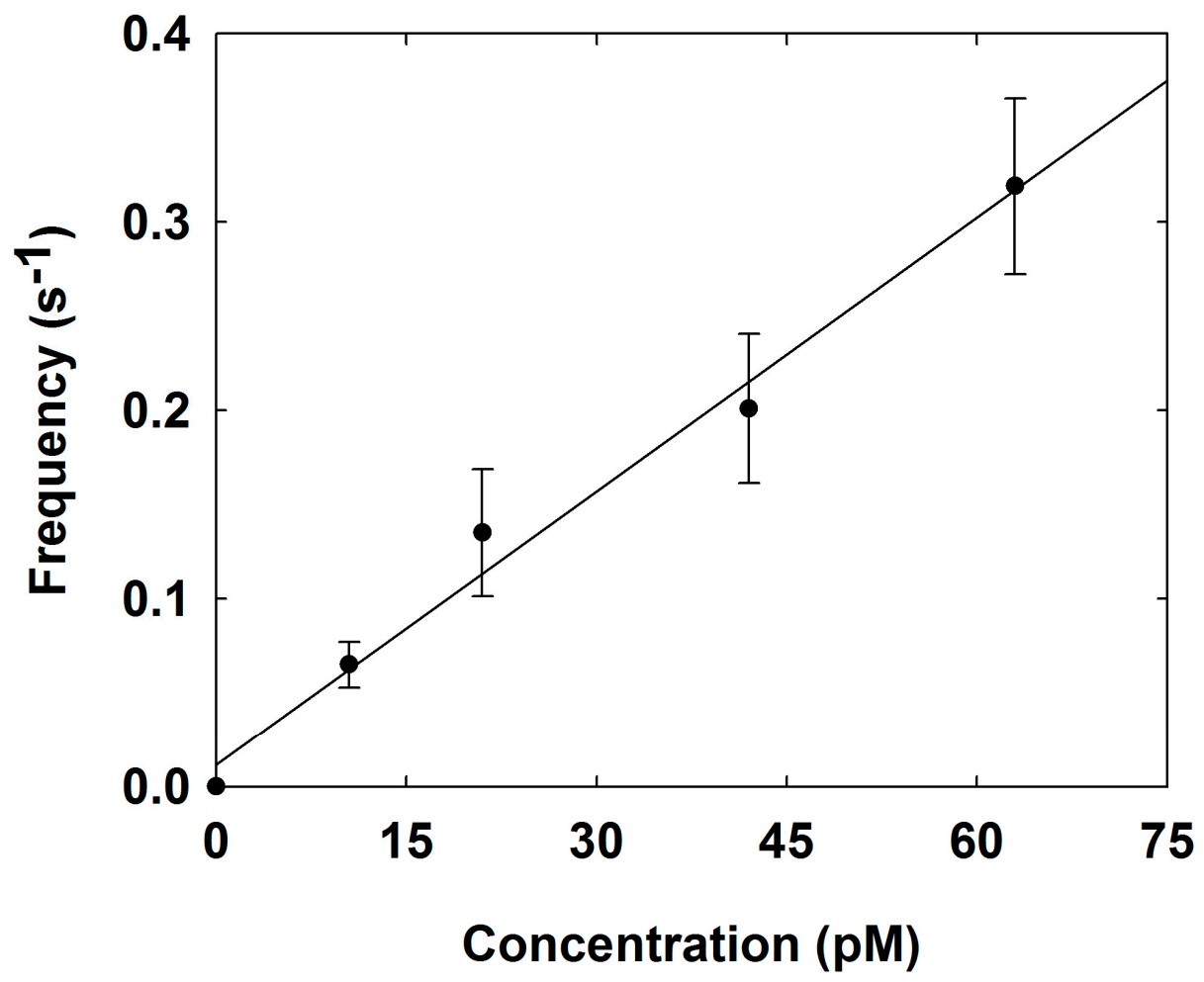

Figure 4. Collision frequency as a function of Pd NP concentration at an applied potential of $-0.15 \mathrm{~V}$ at the Au UME in a $0.1 \mathrm{M}$ PB solution containing $20 \mathrm{mM} \mathrm{H}_{2} \mathrm{O}_{2}$ (for 4 replicate measurements). 
The frequency and the peak intensity of the current signal were investigated. The theoretical steady-state current value by NP, $I_{S S, N P}$, could be calculated by the following equation [4]:

$$
I_{S S, N P}=4 \pi \ln 2 n F D_{H_{2} \mathrm{O}_{2}} C_{\mathrm{H}_{2} \mathrm{O}_{2}} r_{N P}
$$

where $n$ is the number of electrons, $F$ is the Faraday coefficient, $D_{\mathrm{H}_{2} \mathrm{O}_{2}}$ is the diffusion coefficient of hydrogen peroxide, $\mathrm{C}_{\mathrm{H}_{2} \mathrm{O}_{2}}$ is the concentration of hydrogen peroxide, and $r_{N P}$ is the radius of the NP. Here, the diffusion coefficient of hydrogen peroxide, $D_{\mathrm{H}_{2} \mathrm{O}_{2}}$, is estimated by following equation [34]:

$$
I_{S S, U M E}=4 n F D_{\mathrm{H}_{2} \mathrm{O}_{2}} \mathrm{C}_{\mathrm{H}_{2} \mathrm{O}_{2}} r_{U M E}
$$

where $I_{S S, U M E}$ is the steady-state current of the UME, $r_{U M E}$ is the radius of the UME. The diffusion coefficient, $2.59 \times 10^{-5} \mathrm{~cm}^{2} \mathrm{~s}^{-1}$, was obtained from the Figure 1 using a steady-state current of $0.6 \mu \mathrm{A}$ at the $30 \mathrm{mM}$ of hydrogen peroxide concentration, a $10 \mu \mathrm{m}$ radius of the $\mathrm{Pd} \mathrm{UME}$, and a two-electron transfer reaction.

As a result of the calculation above, the theoretical steady-state current by single Pd NP was $479 \mathrm{pA}$. However, the experimentally applied potential, $-0.15 \mathrm{~V}$, is not the potential for steady-state region. It is slightly lower than the steady-state value. Therefore, we multiplied a ratio factor, 0.83 , to obtain the final estimated current, $399 \mathrm{pA}$, which is the expected current at $-0.15 \mathrm{~V}$ where the chronoamperometric measurement was done to prevent background current fluctuation. The experimentally obtained current steps ranged from 20 to $600 \mathrm{pA}$ with average value of 110 ( \pm 90$) \mathrm{pA}$ (Figure S4), which is of the same order of magnitude as the theoretical value. We didn't count the current step below $20 \mathrm{pA}$, because it is difficult to distinguish from noise. The relatively smaller experimental current step compared to the calculation may be due to the lower electrocatalytic activity of Pd NP on Au UME, competition with other reactions, or aggregation of NPs. If the NP became bigger by aggregation, the diffusion coefficient is decreased. Therefore, the collision probability of bigger particle during the experimental time domain, $\sim 300 \mathrm{~s}$, is decreased, so the contribution by small particle is dominant at a short time domain.

\section{Conclusions}

We have investigated the electrocatalytic activity of a single Pd NP for hydrogen peroxide reduction reaction by observing the collision of NP on the Au UME using EA method. The collision event of a single Pd NP was successfully recorded as a staircase current transient with accompanying slow current decay. The hydrogen peroxide reduction has no gas-phase product, the slow decay indicated the deactivation of Pd NP on the Au UME for the hydrogen peroxide reduction. The magnitude of the current generated by the collisions of the NP represents the size distribution of NPs, and the collision frequency is directly proportional to the concentration of the Pd NPs. This observation and analysis of single NP can be used for the identification of a high performance nanocatalyst from numerous NPs or a sensing scheme of ultrasensitive biosensor by employing the nanoparticle and the EA methods as a label and detection system.

Supplementary Materials: The following are available online at http:/ / www.mdpi.com/2079-4991/8/11/879/s1, Figure S1: Cyclic voltammograms of background reaction at Au (black dashed) or Pd (red solid) UME (radius 6.35 and $10 \mu \mathrm{m}$, respectively) in a $0.1 \mathrm{M} \mathrm{PB}$ solution ( $\mathrm{pH}$ 6.8) without $\mathrm{H}_{2} \mathrm{O}_{2}$, Scan rate was $100 \mathrm{mV} / \mathrm{s}$. Figure S2: Chronoamperometric curves for single Pd NP collisions at an applied potential of $-0.3 \mathrm{~V}$ (top) or $-0.2 \mathrm{~V}$ (bottom) at the $\mathrm{Au}$ UME with $10.5 \mathrm{pM}$ of Pd NP concentrations in a $0.1 \mathrm{M}$ PB solution containing $10 \mathrm{mM} \mathrm{H}_{2} \mathrm{O}_{2}$. The data acquisition time was $50 \mathrm{~ms}$. Figure S3: Chronoamperometric curves for single Pd NP collisions at $-0.15 \mathrm{~V}$ applied the $\mathrm{Au}$ UME with $10.5 \mathrm{pM}$ of Pd NP concentrations in a $0.1 \mathrm{M} \mathrm{PB}$ solution containing various $\mathrm{H}_{2} \mathrm{O}_{2}$ concentrations $(10 \mathrm{mM}, 20 \mathrm{mM}$, and $30 \mathrm{mM})$. Figure S4: Distribution of current height of single Pd NP collision. Figure S5: TEM image of Pd NP and its energy-dispersive X-ray spectroscopy (EDX) analysis. The scale bar is $500 \mathrm{~nm}$. Figure S6: Photo of electrochemical set-up its schematic illustration.

Author Contributions: Conceptualization, J.Y.P.; methodology, J.Y.P.; investigation, K.J.K.; data curation, J.Y.P. and H.S.; writing —original draft preparation, S.J.K.; writing—review and editing, K.J.K.; supervision, S.J.K. 
Funding: This research received no external funding.

Acknowledgments: This work was supported by Konkuk University in 2017.

Conflicts of Interest: The authors declare no conflict of interest.

\section{References}

1. Sönnichsen, C.; Reinhard, B.M.; Liphardt, J.; Alivisatos, P. A molecular ruler based on plasmon coupling of single gold and silver nanoparticles. Nat. Biotechnol. 2005, 23, 741-745. [CrossRef] [PubMed]

2. Fan, F.-R.F.; Bard, A.J. An electrochemical coulomb staircase: Detection of single electron-transfer events at nanometer electrodes. Science 1997, 277, 1791-1793. [CrossRef]

3. Xiao, X.; Bard, A.J. Observing single nanoparticle collisions at an ultramicroelectrode by electrocatalytic amplification. J. Am. Chem. Soc. 2007, 129, 9610-9612. [CrossRef] [PubMed]

4. Xiao, X.; Fan, F.-R.F.; Zhou, J.; Bard, A.J. Current transient in single nanoparticle collision events. J. Am. Chem. Soc. 2008, 130, 16669-16677. [CrossRef] [PubMed]

5. Kwon, S.J.; Fan, F.-R.F.; Bard, A.J. Observing Iridium oxide $\left(\mathrm{IrO}_{\mathrm{x}}\right)$ single nanoparticle collisions at ultramicroelectrodes. J. Am. Chem. Soc. 2010, 132, 13165-13167. [CrossRef] [PubMed]

6. Zhou, Y.-G.; Rees, N.V.; Compton, R.G. The electrochemical detection and characterization of silver nanoparticles in aqueous solution. Angew. Chem. Int. Ed. 2011, 50, 4219-4221. [CrossRef] [PubMed]

7. Quinn, B.M.; van't Hof, P.G.; Lemay, S.G. Time-resolved electrochemical detection of discrete adsorption events. J. Am. Chem. Soc. 2004, 126, 8360-8361. [CrossRef] [PubMed]

8. Kleijn, S.E.F.; Lai, S.C.S.; Miller, T.S.; Yanson, A.I.; Koper, M.T.M.; Unwin, P.R. Landing and catalytic characterization of individual nanoparticles on electrode surfaces. J. Am. Chem. Soc. 2012, 134, 18558-18561. [CrossRef] [PubMed]

9. Fosdick, S.E.; Anderson, M.J.; Nettleton, E.G.; Crooks, R.M. Correlated electrochemical and optical tracking of discrete collision events. J. Am. Chem. Soc. 2013, 135, 5994-5997. [CrossRef] [PubMed]

10. Dasari, R.; Robinson, D.A.; Stevenson, K.J. Ultrasensitive electroanalytical tool for detecting, sizing, and evaluating the catalytic activity of platinum nanoparticles. J. Am. Chem. Soc. 2013, 135, 570-573. [CrossRef] [PubMed]

11. Guo, Z.-H.; Percival, S.J.; Zhang, B. Chemically resolved transient collision events of single electrocatalytic nanoparticles. J. Am. Chem. Soc. 2014, 136, 8879-8882. [CrossRef] [PubMed]

12. Fernando, A.; Parajuli, F.; Alpuche-Aviles, M.A. Observation of individual semiconducting nanoparticle collisions by stochastic photoelectrochemical currents. J. Am. Chem. Soc. 2013, 135, 10894-10897. [CrossRef] [PubMed]

13. Chen, C.-H.; Ravenhill, E.R.; Momotenko, D.; Kim, Y.-R.; Lai, S.C.S.; Unwin, P.R. Impact of surface chemistry on nanoparticle-electrode interactions in the electrochemical detection of nanoparticle collisions. Langmuir 2015, 31, 11932-11942. [CrossRef] [PubMed]

14. Ustarroz, J.; Kang, M.; Bullions, E.; Unwin, P.R. Impact and oxidation of single silver nanoparticles at electrode surface: One shot versus multiple events. Chem. Sci. 2017, 8, 1841-1853. [CrossRef] [PubMed]

15. Zhou, H.; Park, J.H.; Fan, F.-R.F.; Bard, A.J. Observation of single metal nanoparticle collisions by open circuit (mixed) potential changes at an ultramircoelectrode. J. Am. Chem. Soc. 2012, 134, 13212-13215. [CrossRef] [PubMed]

16. Dasari, R.; Robinson, D.A.; Stevenson, K.J. Electrochemical Monitoring of Single Nanoparticle Collisions at Mercury-Modified Platinum Ultramicroelectrodes. ACS Nano 2014, 8, 4539-4546. [CrossRef] [PubMed]

17. Zhou, Y.-G.; Rees, N.V.; Pillay, J.; Tshikhudo, R.; Vilakazi, S.; Compton, R.G. Gold nanoparticles show electroactivity: Counting and sorting nanoparticles upon impact with electrodes. Chem. Commun. 2012, 48, 224-226. [CrossRef] [PubMed]

18. Haddou, B.; Rees, N.V.; Compton, R.G. Nanoparticle-electrode impacts: The oxidation of copper nanoparticles has slow kinetics. Phys. Chem. Chem. Phys. 2012, 14, 13612-13617. [CrossRef] [PubMed]

19. Boika, A.; Thorgaard, S.N.; Bard, A.J. Monitoring the electrophoretic migration and adsorption of single insulating nanoparticles at ultramicroelectrodes. J. Phys. Chem. B 2013, 117, 4371-4380. [CrossRef] [PubMed]

20. Kim, B.K.; Kim, J.; Bard, A.J. Electrochemistry of a single attoliter emulsion droplet in collisions. J. Am. Chem. Soc. 2015, 137, 2343-2349. [CrossRef] [PubMed] 
21. Dick, J.E.; Hilterbrand, A.T.; Boika, A.; Upton, J.W.; Bard, A.J. Electrochemical detection of single cytomegalovirus at an ultramicroelectrode and its antibody anchoring. Proc. Natl. Acad. Sci. USA 2015, 112, 5303-5308. [CrossRef] [PubMed]

22. Dick, J.E.; Renault, C.; Bard, A.J. Obeservation of single-protein and DNA macromolecule collisions on ultramicroelectrodes. J. Am. Chem. Soc. 2015, 137, 8376-8379. [CrossRef] [PubMed]

23. Safavi, A.; Maleki, N.; Tajabadi, F.; Farjami, E. High electrocatalytic effect of palladium nanoparticle arrays electrodeposited on carbon ionic liquid electrode. Electrochem. Commun. 2007, 9, 1963-1968. [CrossRef]

24. Chen, X.-M.; Cai, Z.-X.; Huang, Z.-Y.; Oyama, M.; Jiang, Y.-Q.; Chen, X. Ultrafine palladium nanoparticles grown on graphene nanosheets for enhanced electrochemical sensing of hydrogen peroxide. Electrochim. Acta 2013, 97, 398-403. [CrossRef]

25. You, J.-M.; Jeong, Y.N.; Ahmed, M.S.; Kim, S.K.; Choi, H.C.; Jeon, S. Reductive determination of hydrogen peroxide with MWCNTs-Pd nanoparticles on a modified glassy carbon electrode. Biosens. Bioelectron. 2011, 26, 2287-2291. [CrossRef] [PubMed]

26. Daryanavard, N.; Zare, H.R. Single Palladium nanoparticle collisions detection through chronopotentiometric method: Introducing a new approach to improve the snalytical signals. Anal. Chem. 2017, 89, 8901-8907. [CrossRef] [PubMed]

27. Kang, M.; Perry, D.; Kim, Y.-R.; Colburn, A.W.; Lazenby, R.A.; Unwin, P.R. Time-resolved detection and analysis of single nanoparticle electrocatalytic impacts. J. Am. Chem. Soc. 2015, 137, 10902-10905. [CrossRef] [PubMed]

28. Stuart, E.J.E.; Rees, N.V.; Compton, R.G. Particle-impact voltammetry: The reduction of hydrogen peroxide at silver nanoparticles impacting a carbon electrode. Chem. Phys. Lett. 2012, 531, 94-97. [CrossRef]

29. Jung, A.R.; Lee, S.; Joo, J.W.; Shin, C.; Bae, H.; Moon, S.G.; Kwon, S.J. Potential-controlled current responses from staircase to blip in single Pt nanoparticle collisions on a Ni ultramicroelectrode. J. Am. Chem. Soc. 2015, 137, 1762-1765. [CrossRef] [PubMed]

30. Guo, Y.; Xu, Y.-T.; Gao, G.-H.; Wang, T.; Zhao, B.; Fu, X.-Z.; Sung, R.; Wong, C.-P. Electro-oxidation of formaldehyde and methanol over hollow porous palladium nanoparticles with enhanced catalytic activity. Catal. Commun. 2015. [CrossRef]

31. Kim, J.J.; Choi, Y.S.; Kwon, S.J. Study on Electrocatalytic water oxidation reaction by Iridium oxide and its bubble overpotential Effect. J. Korean Electrochem. Soc. 2013, 16, 70-73. [CrossRef]

32. Kwon, S.J.; Bard, A.J. Analysis of diffusion-controlled stochastic events of iridium oxide single nanoparticle collisions by scanning electrochemical microscopy. J. Am. Chem. Soc. 2012, 134, 7102-7108. [CrossRef] [PubMed]

33. Kwon, S.J.; Zhou, H.; Fan, F.-R.F.; Vorobyev, V.; Zhang, B.; Bard, A.J. Stochastic electrochemistry with electrocatalytic nanoparticles at inert ultramicroelectrodes-Theory and experiments. Phys. Chem. Chem. Phys. 2011, 13, 5394-5402. [CrossRef] [PubMed]

34. Bard, A.J.; Faulkner, L.R. Ectrochemical Methods, Fundamentals and Applications, 2nd ed.; John Wiley \& Sons: New York, NY, USA, 2001.

(C) 2018 by the authors. Licensee MDPI, Basel, Switzerland. This article is an open access article distributed under the terms and conditions of the Creative Commons Attribution (CC BY) license (http://creativecommons.org/licenses/by/4.0/). 